\title{
Homeobox gene expression in acute myeloid leukemia is linked to typical underlying molecular aberrations
}

Karolina Skvarova Kramarzova', Karel Fiser ${ }^{1}$, Ester Mejstrikova ${ }^{1,2}$, Katerina Rejlova', Marketa Zaliova', Maarten Fornerod ${ }^{4,6}$, Harry A Drabkin ${ }^{5}$, Marry M van den Heuvel-Eibrink ${ }^{4}$, Jan Stary ${ }^{3}$, Jan Trka ${ }^{1,2^{*}}$ and Julia Starkova ${ }^{1}$

\begin{abstract}
Background: Although distinct patterns of homeobox (HOX) gene expression have been described in defined cytogenetic and molecular subsets of patients with acute myeloid leukemia (AML), it is unknown whether these patterns are the direct result of transcriptional alterations or rather represent the differentiation stage of the leukemic cell.
\end{abstract}

Method: To address this question, we used QPCR to analyze mRNA expression of HOXA and HOXB genes in bone marrow (BM) samples of 46 patients with AML and sorted subpopulations of healthy BM cells. These various stages of myeloid differentiation represent matched counterparts of morphological subgroups of AML. To further study the transcriptional alterations of HOX genes in hematopoiesis, we also analyzed gene expression of epigenetic modifiers in the subpopluations of healthy BM and leukemic cells.

Results: Unsupervised hierarchical clustering divided the AMLs into five clusters characterized by the presence of prevalent molecular genetic aberrations. Notably, the impact of genotype on HOX gene expression was significantly more pronounced than that of the differentiation stage of the blasts. This driving role of molecular aberrations was best exemplified by the repressive effect of the PML-RARa fusion gene on HOX gene expression, regardless of the presence of the FLT3/ITD mutation. Furthermore, HOX gene expression was positively correlated with mRNA levels of histone demethylases (JMJD3 and UTX) and negatively correlated with gene expression of DNA methyltranferases. No such relationships were observed in subpopulations of healthy BM cells.

Conclusion: Our results demonstrate that specific molecular genetic aberrations, rather than differentiation per se, underlie the observed differences in HOX gene expression in AML. Moreover, the observed correlations between epigenetic modifiers and HOX ex pression that are specific to malignant hematopoiesis, suggest their potential causal relationships.

Keywords: Acute myeloid leukemia, Homeobox genes, Myelopoiesis, Epigenetic modifiers

\footnotetext{
* Correspondence: jan.trka@lfmotol.cuni.cz

${ }^{1}$ CLIP-Childhood Leukaemia Investigation Prague, Department of Paediatric

Hematology and Oncology, 2nd Faculty of Medicine, Charles University

Prague, Prague, Czech Republic

${ }^{2}$ CLIP-Childhood Leukaemia Investigation Prague, Department of Paediatric

Hematology and Oncology, 2nd Faculty of Medicine, University Hospital

Motol, Prague, Czech Republic

Full list of author information is available at the end of the article
}

( Biomed Central

(c) 2014 Skvarova Kramarzova et al.; licensee BioMed Central. This is an Open Access article distributed under the terms of the Creative Commons Attribution License (http://creativecommons.org/licenses/by/4.0), which permits unrestricted use,

distribution, and reproduction in any medium, provided the original work is properly credited. The Creative Commons Public Domain Dedication waiver (http://creativecommons.org/publicdomain/zero/1.0/) applies to the data made available in this article, unless otherwise stated. 


\section{Introduction}

The clustered homeobox $(H O X)$ genes encode a large family of transcription factors characterized by the presence of a highly conserved nucleotide sequence called the homeodomain. This 61-amino-acid helix-turn-helix domain is responsible for the binding of HOX proteins to their target DNA sequences. In humans, the $39 \mathrm{HOX}$ genes are organized into four genomic regions (the HOXA, $B, C$ and $D$ clusters) located on four chromosomes (chromosomes 7, 17, 12 and 2, respectively). Each cluster consists of $9-11$ genes arranged in the same orientation and in paralogous groups $[1,2]$.

$H O X$ genes play essential roles during embryogenesis by controlling cell fate along the anterior-posterior axis and specifying segment identity [3-5]. The characteristic expression of $H O X$ genes can also be detected in various adult tissues [6,7]. During hematopoiesis, the highest expression of $H O X$ genes occurs in the stem and early hematopoietic progenitor cells. During maturation, $H O X$ expression gradually decreases, and it is minimal in differentiated hematopoietic cells $[8,9]$. The expression of $H O X$ genes throughout the maturation of hematopoietic cells is tightly regulated, suggesting that disruption of this regulation contributes to the process of malignant transformation.

The oncogenic potential of $H O X$ genes in leukemia has been intensively studied for more than two decades. Several chromosomal translocations in leukemia involve $H O X$ genes either directly (e.g., NUP98-HOX fusion) or via their upstream regulators (e.g., MLL rearrangements) [10-13]. Moreover, the overexpression of certain $H O X$ genes and their cofactors are known as poor prognostic markers in leukemia patients [14-16]. The overexpression of $H O X$ genes is believed to induce myeloproliferation, which together with additional aberrations, may lead to leukemia.

The regulation of gene expression during hematopoiesis is controlled by the cooperation of transcription factors and the dynamic architecture of chromatin. The specific epigenetic landscape influences target gene accessibility. As major executors of epigenetic regulation, chromatin-modifying enzymes mediate DNA and histone modifications responsible for the unique dynamics of chromatin observed throughout hematopoiesis. The deregulation of this process likely contributes to the malignant transformation of hematopoietic cells.

In embryogenesis, spatio-temporal expression of $H O X$ genes is regulated by the trithorax-group (TrxG) and polycomb-group (PcG) proteins. PcG genes maintain $H O X$ gene silencing through methylation of histone 3 lysine 27 (H3K27). In contrast, TrxG genes are responsible for maintaining previously established $H O X$ gene expression through trimethylation of histone 3 lysine 4 (H3K4) [8,17]. A similar effect of $P c G$ and $\operatorname{Tr} x G$ genes has been proposed in the regulation of $H O X$ gene expression in hematopoiesis as suggested by the severe defects of hematopoietic cells that have been reported in $P c G$ and $\operatorname{Tr} x G$ knock-out models $[18,19]$. In addition, the H3K4 demethylase LSD1 and JmjC-domain-containing H3K27 demethylases JMJD3 (KDM6B) and UTX (KDM6A) have been shown to contribute to $H O X$ gene regulation in embryonic development [20,21]. LSD1 establishes an inactive chromatin configuration by H3K4 demethylation, whereas JMJD3 and UTX activate chromatin by demethylation of H3K27. Finally, DNA methylation has been shown to participate in the establishment of $H O X$ gene expression patterns, further supporting the role of epigenetics in the regulation of these genes [22].

In this paper, we sought to determine whether the pattern of leukemic HOX gene expression was primarily driven by the differentiation stage of hematopoietic cells or determined de novo during the process of malignant transformation. To approach this question, the expression patterns of the HOX genes were correlated with the molecular genetics and morphological characteristics of the leukemic cells of patients with childhood acute myeloid leukemia (AML). To further study the regulation of $H O X$ gene expression, we also examined the relationships of chromatin modifiers and $H O X$ genes in normal and malignant myelopoiesis.

\section{Methods}

BM samples of healthy donors and patients with AML

Subpopulations of healthy BM representing developmental stages of hematopoiesis were sorted from the samples of healthy volunteers or minimal residual disease (MRD)negative leukemia patients in long-term complete remission (Fluorescence Activated Cell Sorter (FACS) Aria, BD, San Jose, CA, USA). The combination of surface markers that was used to identify the particular stages of myeloid lineage differentiation is listed in Table 1 . To ensure adequate analysis sensitivity, we pooled the sorted samples of each subpopulation from five control donors and processed them as described below.

In total, 46 patients with childhood AML enrolled in the study were diagnosed and treated from 1998 to 2010 at the Czech Pediatric Hematology Working Group centers (Additional file 1: Table S1). Following the University Hospital Motol ethical committee's approval number P304/12/2214 and written informed consent, mononuclear cells were isolated from the diagnostic BM samples using a density gradient medium (Ficoll-Paque Plus, GE Healthcare Life Sciences, Uppsala, Sweden) and stored at $-80^{\circ} \mathrm{C}$.

RNA from both the patient samples and the healthy donor BM subpopulations were isolated with RNeasy Mini Kit (Qiagen, Hilden, Germany) and transcribed to cDNA using the iScript kit (Bio-Rad, Hercules, CA, USA). 
Table 1 Identification of subpopulations of healthy BM cells

\begin{tabular}{|c|c|c|c|c|}
\hline & \multicolumn{2}{|c|}{ Normal sorted populations of myeloid lineage } & \multicolumn{2}{|c|}{ Counterparts with FAB AML } \\
\hline & \multicolumn{4}{|c|}{ Granulocyte lineage subpopulations } \\
\hline G1 & myeloid progenitor & CD117+CD15-CD11b- & AML M1 & AML M2 \\
\hline G2 & promyelocyte & $C D 117+C D 15+C D 11 b-$ & AML M3 & AML M2 \\
\hline G3 & promyelocyte-myelocyte & CD117-CD13++CD16- & & \\
\hline \multirow[t]{2}{*}{ G4 } & myelocyte & CD117-CD13dimCD16- & & \\
\hline & \multicolumn{4}{|c|}{ Monocyte lineage subpopulations } \\
\hline M1 & myeloblast & $\mathrm{CD} 34+\mathrm{SSC}++\mathrm{HLA} \mathrm{DR}+\mathrm{CD} 33-$ & AML M1 & \\
\hline M2 & myelo/monoblast & CD34+Ssc++HLA DR+CD33+ & AML M2 & \\
\hline M3 & promonocyte & CD34-FSc and Ssc corresponding to monocytes CD33+CD14- & AML M4 & \\
\hline M4 & monocyte & CD34-FSC and Ssc corresponding to monocytes CD33+CD14+ & AML M5 & \\
\hline
\end{tabular}

Main characteristics of stages of myeloid lineage differentiation - surface markers and their counterparts with morphological subtypes of AML.

Real-time quantitative polymerase chain reaction (qPCR) The quantification of gene expression was performed using the iCycler iQ System (BioRad, Hercules, CA, USA). The primer design and qPCR conditions for amplification of the $H O X A$ and $H O X B$ genes in the sorted populations (HOXA3, A4, A5, A6, A7, A9, A10, B2, B4, B5, B6, and $B 7)$ and patient samples (HOXA1, A3, A4, A5, A6, A7, $A 9, A 10, A 11, A 13, B 1, B 2, B 4, B 5, B 6, B 7, B 8$, and $B 9$ ) as well as the chromatin modifier genes (PcG family: EZH2 and BMI1; Trx family: MLL; DNMTs: DNMT1, $D N M T 3 a$, and DNMT3b and histone demethylases: JMJD3, $U T X$ and $L S D 1$ ) were performed as previously described [14,15,20,23-25]. To normalize the gene expression levels, we used the $A B L 1$ gene, which is known to be stably expressed during the development of myeloid lineage cells.

\section{Mutation analysis}

The mutation statuses of the NPMI, NRAS, KRAS, CEBPa, $c$-KIT and FLT3 genes were determined in 12 patients for whom material was available and who were negative for the presence of the four major molecular aberrations (Additional file 1: Table S1). The analysis was performed by qualitative PCR followed by the sequencing of particular amplicons with the primers and PCR conditions as described earlier [26-29].

\section{Statistical analysis}

Data were analyzed using the statistical software packages Prism (GraphPad, La Jolla, CA, USA), Excel (Microsoft Corporation, Redmond, WA, USA), StatView (SAS Institute, Cary, NC, USA) and R-project (Vienna, Austria). The statistical significance of the differences among the subgroups of samples was assessed using non-parametric tests (Mann-Whitney and Kruskal-Wallis tests with Dunn's multiple comparison post test). Gene expression correlations were estimated by Spearman's rank correlation.
Unsupervised hierarchical cluster analysis (HCA), performed with the Genesis software (Institute for Genomics and Bioinformatics, Graz University of Technology (IGB-TUG), Graz, Austria), was used to identify the subgroups of samples with similar gene expression patterns.

\section{Results}

Expression patterns of HOX genes in sorted subpopulations of healthy BM cells representing different stages of myelopoiesis

Using FACS, we obtained eight subpopulations of normal BM donor cells, based on characteristic surface markers, which represent distinct stages of myeloid differentiation. The subpopulations corresponding with particular maturation stages were selected based on our expertise and previously published studies (Table 1) [30-32]. Notably, we frequently observed the asynchronous expression of antigens and the overlap of immunophenotypic maturation stages in the leukemic blasts.

To better demonstrate the dynamics of $H O X$ gene expression throughout hematopoiesis, data from the subpopulations of the two developmental lineages of myelopoises (granulocytic and monocytic) with the parallel differentiation stage were pooled together. This resulted in the discernment of four consecutive stages of myeloid development (stage $1=\mathrm{G} 1+\mathrm{M} 1$, stage $2=\mathrm{G} 2+$ $\mathrm{M} 2$, stage $3=\mathrm{G} 3+\mathrm{M} 3$ and stage $4=\mathrm{G} 4+\mathrm{M} 4$ ). In accordance with previously published data, the expression of HOXA and particular HOXB (HOXB2 and HOXB4) genes gradually decreased during myeloid maturation (Figure 1A and Additional file 2: Figure S1). As assessed by comparisons on an one-to-one basis we also observed a clear positive correlation of $H O X$ gene expression within $H O X A$ cluster and $H O X B$ cluster as well as between both clusters (Additional file 3: Figure S2). 


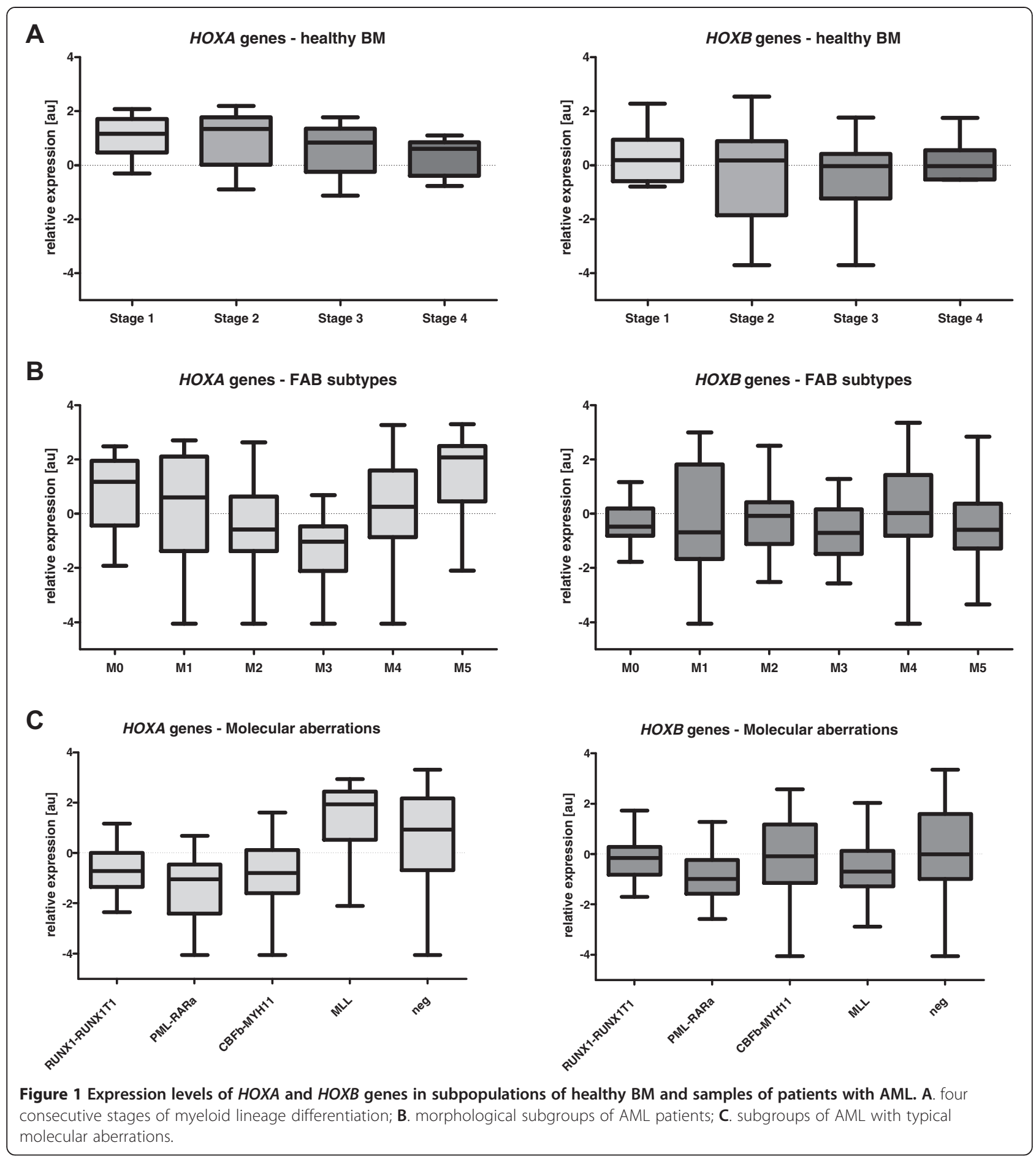

Expression patterns of $\mathrm{HOX}$ genes in $\mathrm{BM}$ samples from patients with childhood AML

Distinctive $H O X$ gene expression patterns were observed among the French-American-British classification (FAB) AML subtypes (Kruskal-Wallis test: $\mathrm{p}<0.0001$ for the $H O X A$ and $\mathrm{p}=0.0016$ for the $H O X B$ cluster; Figure $1 \mathrm{~B}$ and Additional file 4: Figure S3). The M3 FAB subtype had the lowest levels of $H O X A$ and $H O X B$ gene expression compared with other FAB subtypes (see Additional file 4: Figure S3). In contrast, AML M5 had the highest $H O X A$ gene expression levels, along with the largest number of individual $H O X A$ genes showing significant differential expression (Additional file 4: Figure S3). Significant differences were also found among subgroups defined according to molecular genetics (i.e., Kruskal-Wallis test: $\mathrm{p}<0.0001$ for the $H O X A$ and $\mathrm{p}=0.0001$ for the $H O X B$ 
cluster; Figure $1 \mathrm{C}$ and Additional file 5: Figure S4). Patients with $P M L-R A R a$ fusion showed the lowest levels of $H O X A$ and $H O X B$ gene expression, while those with $M L L$ rearrangements expressed $H O X A$ genes at the highest levels (the majority of individual $H O X$ gene comparisons revealed significant differential expression in the $P M L-R A R a$ and $M L L+$ patients, respectively). Moreover, unsupervised hierarchical clustering based on $H O X$ expression divided the leukemias into five main clusters characterized by the presence or absence of prevalent gene rearrangements, i.e., $P M L-R A R a$, RUNX1-RUNX1T1(AML1-ETO), CBFb-MYH11 and MLL alterations (Additional file 6: Figure S5). Interestingly, three patients from cluster 1 (i.e., those having the overall highest levels of $H O X$ gene expression and absence of these translocations) harbored a mutation in the NPM1 gene, similar to what has been reported in adult AML [16].

High risk (HR) patients expressed HOXA genes at significantly higher levels compared with patients who were assigned to the standard risk (SR) group ( $\mathrm{p}<0.0001$ for HOXA3 - A13 and $\mathrm{p}=0.0004$ for HOXA1). However, no differences were observed in $H O X B$ expression between high and low risk patients. In addition, both HOXA and $H O X B$ gene expression were not found to be related to the patient age or risk stratification (Additional file 7: Figure S6; risk group stratification of childhood AML (AML-BFM 98 and 2004): standard risk - FAB M1/M2 with Auer rods, M3, M4eo, Down sy, $\mathrm{t}(8 ; 21), \mathrm{t}(15 ; 17)$, $\operatorname{inv}(16)$, and $\leq 5 \%$ of blasts in BM at D15 (except M3); high risk - others).

Impact of molecular aberrations on HOX gene expression within the morphological subgroups of $A M L$

The effects of genetic aberrations on HOX gene expression were even more apparent when analyzed within the morphological FAB subtypes. In AML M4, the CBFb$M Y H 11+$ patients exhibited statistically significant levels of lower $H O X$ expression compared with those lacking the rearrangement. For AML M2, the RUNX1-RUNX1T1+ patients tended to show reduced levels of $H O X$ gene expression compared with patients without the rearrangement (Figure 2A and 2B; p values indicated in figure legend).

\section{Different effect of FLT3/ITD on HOX gene expression in the presence of PML-RARa fusion gene}

In adults with normal cytogenetic AML, NPMI1 mutations are associated with high $H O X$ expression and those leukemias have a higher frequency of FLT3 mutations [33]. In our samples, HOX gene expression in the PML-RARa+ patients remained at very low levels regardless of the presence of FLT3/ITD mutations (FLT3/ITD+ $(\mathrm{N}=4)$ vs. FLT3/ITD- $(\mathrm{N}=4)$; Figure $3 \mathrm{~A}$; p values indicated in figure legend). In contrast, in the absence of a $P M L$ -
RARa fusion, HOX levels were higher when FLT3 was mutated. These results were further emphasized by the analysis of gene expression data from a larger $(\mathrm{N}=48)$ independent cohort of FLT3/ITD+ childhood AML patients [34], which demonstrated that HOXA and $H O X B$ gene levels were significantly reduced in FLT3/ITD+ patients with $P M L-R A R a(\mathrm{~N}=12)$ compared to those without the fusion gene $(\mathrm{N}=36$; Figure $3 \mathrm{~B})$.

\section{HOX gene expression patterns in corresponding differentiation stages of normal and malignant myelopoiesis}

As indicated above, we sorted the subpopulations of normal BM cells from the healthy donors according to the specific stage of myelopoiesis. Our gating strategy enabled a comparison of these subpopulations with the FAB subtypes of AML patients exhibiting the similar stage of myeloid maturation arrest. The list of AML subtypes assigned to particular stages of myelopoiesis is provided in Table 1. Differential HOX gene expression patterns were identified between the normal and malignant hematopoietic counterparts, as demonstrated by comparing AML M3 with the corresponding stage of promyelocytes (ID = G2). These differences were particularly evident for HOXA5, HOXA6, HOXA9, HOXA10 and HOXB4 (Figure 4). Similarly, differential expression of HOXA3, HOXA4, HOXA5, HOXA6, HOXA7, HOXA9, HOXA10, HOXB5 and HOXB6 distinguished leukemic cells of the M5a and M5b FAB subtypes from the matched normal counterparts, represented by the sorted M3 and M4 population, respectively (Additional file 8: Figure S7A and 7B).

\section{Expression patterns of chromatin modifiers and their role in $H O X$ gene regulation}

In subpopulations of healthy BM cells, we analyzed the expression of chromatin modifying genes, previously shown to contribute to HOXA and HOXB regulation during embryogenesis $[21,35,36]$. Based on observed expression in the sorted subpopulations, the chromatin modifiers were divided into three groups. The first group, "Modifiers 1", included genes that did not exhibit varying expression levels during differentiation (EZH2, BMI1, MLL, LSD1 and DNMT1). The second group, "Modifiers 2", consisted of genes showing increased expression during hematopoiesis (JMJD3 and UTX). Expression levels of the third group, "Modifiers 3" (DNMT3a and DNMT3b), showed a decrease concomitant with differentiation, which were statistically inversely correlated with Modifiers $2(R=-0.922$; Figure 5A). However, we did not observe a clear pattern of corresponding $\mathrm{HOX}$ gene expression changes in these cells.

In leukemic cells, the expression of Modifier 1 genes, except for BMI1, paralleled their normal counterparts, being largely unchanged among the morphological AML 


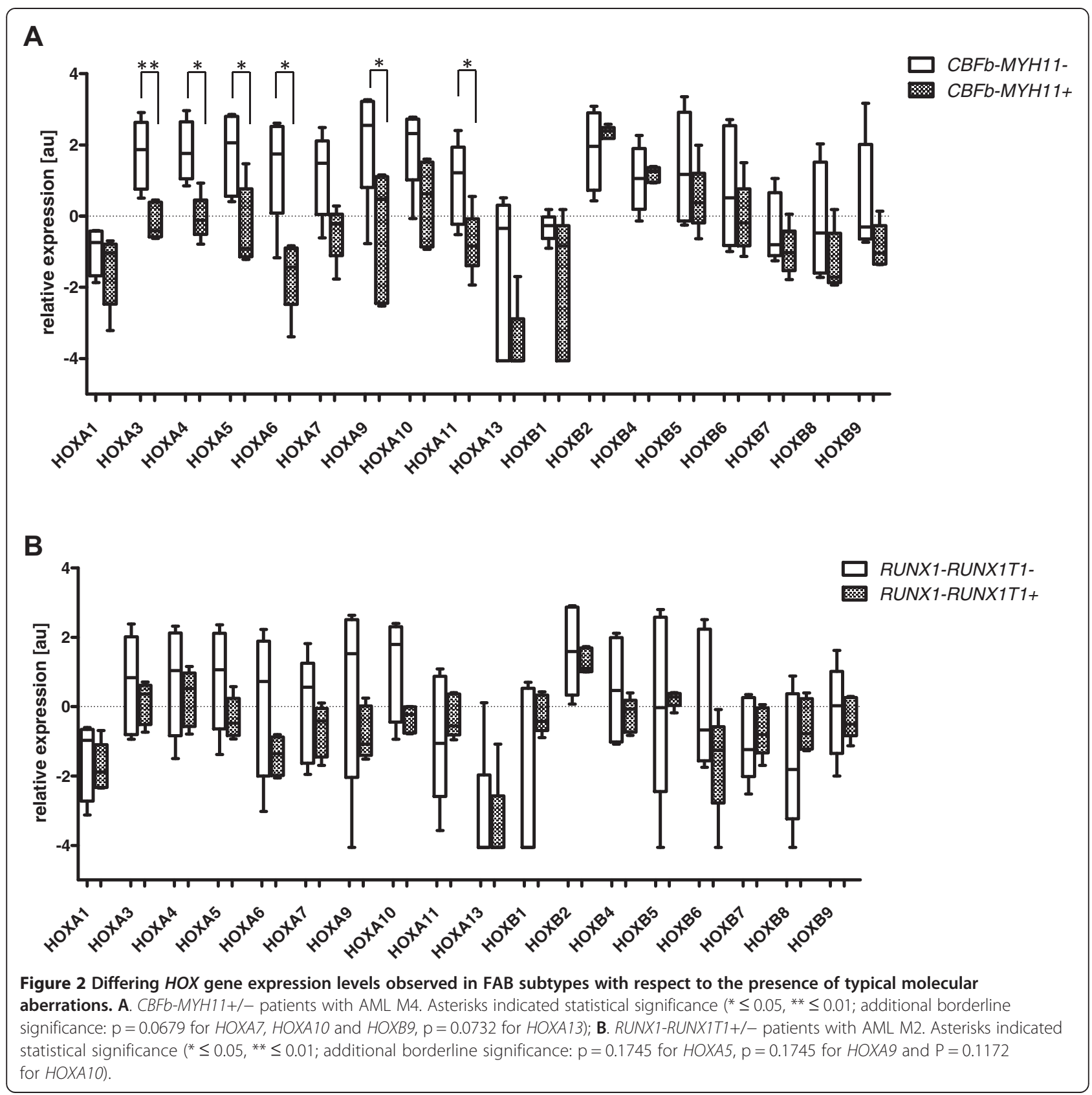

subgroups. The expression of Modifier 2 and 3 genes markedly differed among AML samples (Figure 5B). In contrast to normal cells, the expression of Modifier 2 and 3 genes appeared to mirror the differences in $H O X$ mRNA levels. In general, $H O X B$ expression was positively correlated with Modifier 2 genes (e.g., H3K27 demethylases; $\mathrm{R}=0.874$ ). The correlation of $H O X A$ gene expression levels with Modifiers 2 genes was less pronounced $(R=0.506)$ in all cases with the exception of the AML M3 subgroup. For the Modifier 3 genes (e.g., DNMTs), there was a substantial negative correlation with $H O X B$ expression $(\mathrm{R}=-0.442$; Figure 6). However, in contrast to normal hematopoiesis, the observed inverse correlation between Modifier 2 and 3 genes was much less pronounced (except for AML M3 and $\mathrm{M} 4 ; \mathrm{R}=-0.178$; Figure 6).

For individual genes in the leukemic samples (Additional file 9: Figure S8), there were several notable correlations. For instance, the expression of JMJD3 with HOXB4 and HOXB6 was strongly positively correlated $(\mathrm{p}=0.0003$ and 0.0012 , respectively), while negatively correlated with DNMT3b ( $\mathrm{p}=0.03)$. There was also strong correlation on a one-to-one basis between genes in the HOXA cluster and for genes in the $H O X B$ cluster. However, in contrast with the healthy samples, there was only a weak 


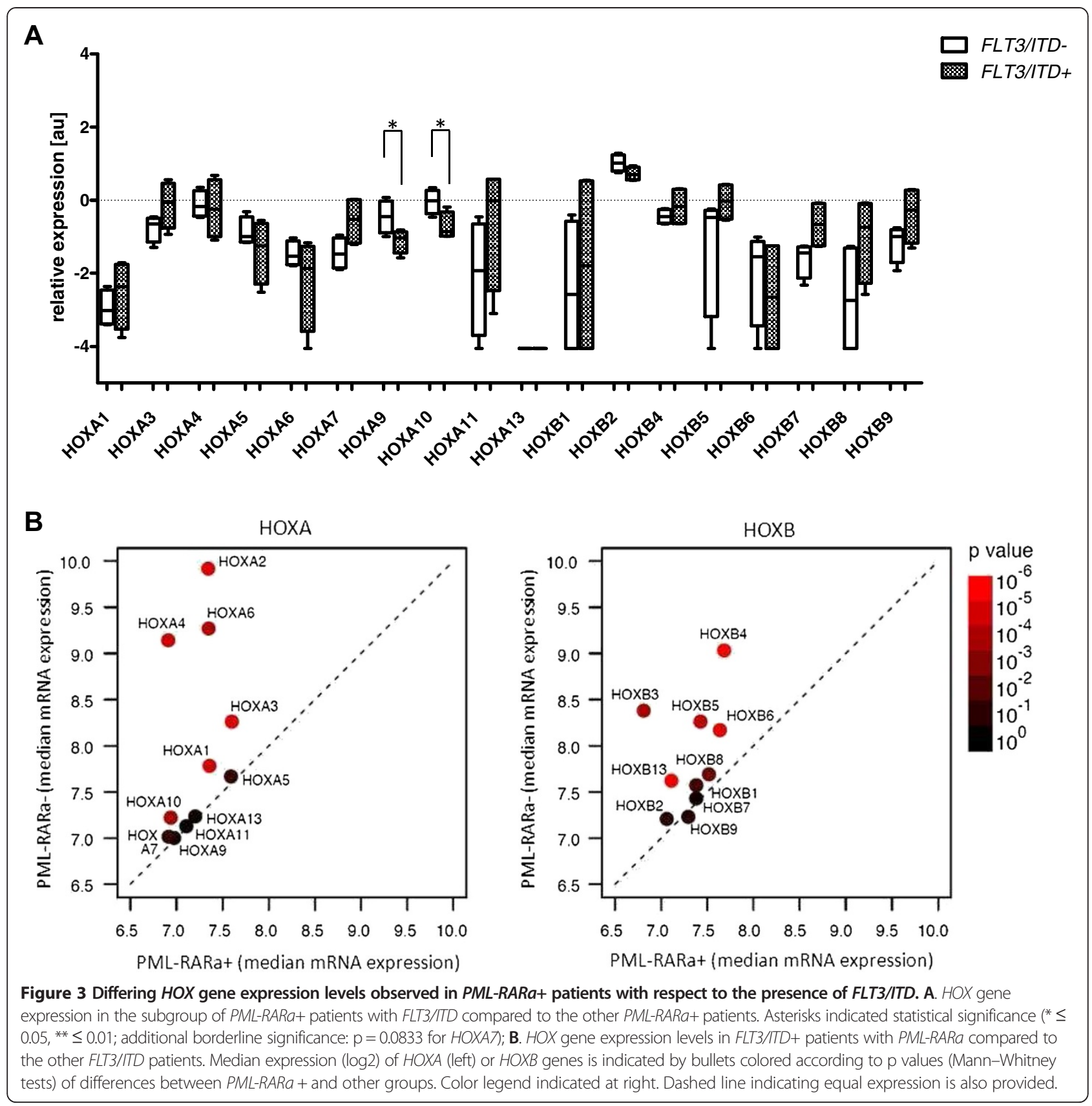

correlation between the particular $H O X$ genes from different $H O X$ clusters.

\section{Discussion}

Several reports have demonstrated that $H O X$ genes are not only potent regulators of embryonic development but also play significant roles in the regulation of many processes in adult organisms, including hematopoiesis [37-39]. The overall role of $H O X$ clusters in addition to that of particular $H O X$ genes in hematopoiesis have been revealed by various knock-out and overexpression studies of human hematopoietic cells or by studies using mouse models [40-43]. However, the degree to which $H O X$ genes contribute to the process of leukemogenesis has not yet been elucidated.

The aberrant expression of HOX genes has been reported in the majority of leukemia patients. However, it remains unknown whether this aberrant expression represents a genuine driver of leukemogenesis or a passenger effect reflecting a differentiation block. Another possible explanation takes into consideration an impact of the molecular aberrations present in leukemic cells with further biological consequences. Here, we attempted to shed light on the expression of $H O X$ genes in normal hematopoietic 


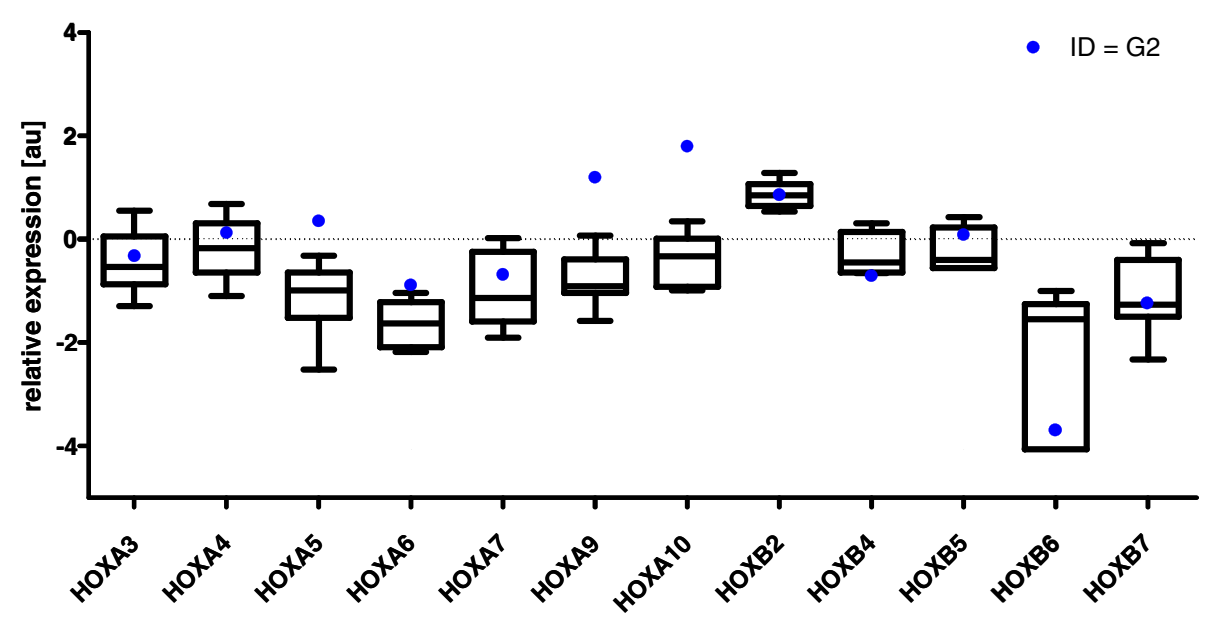

Figure 4 HOX gene expression patterns in corresponding differentiation stages of normal and malignat hematopoiesis. Comparison of HOX gene expression patterns between AML M3 and sorted subpopulation of healthy BM cells (ID = G2).

precursor cells versus their malignant counterparts with respect to their differentiation stage arrest in AML.

The crucial prerequisite for such an analysis is the appropriate identification of subpopulations of healthy BM cells representing the stages of myelopoiesis that can be matched to their respective morphological counterparts in AML. We managed to sort these subpopulations and analyzed their $H O X$ gene expression patterns. The expression of $H O X$ genes was higher at the initial stages of hematopoiesis and gradually decreased with the maturation of the hematopoietic cells, supporting the generally accepted hypothesis that $H O X$ genes are strong regulators of hematopoiesis (particularly at the early stages) [37].

A comparison of matched normal and malignant hematopoietic precursor cells at the same differentiation stage demonstrated the distinct expression patterns of the $H O X$ genes in the leukemic cells. This indicates that the aberrant patterns of $H O X$ gene expression cannot be simply explained by the differentiation statuses at which the cells have been arrested. This is similar to what we previously observed in pediatric patients with ALL, who were found to exhibit differential $H O X$ gene expression between the subgroups and their matched normal precursors according to differentiation stage [15]. Altogether, our results support the hypothesis that the dysregulation of $H O X$ genes is involved in the process of neoplastic transformation.

The analysis of childhood AML patients revealed a different expression profile of $H O X$ genes among the FAB subtypes and the subgroups of patients bearing unique molecular rearrangements. The most diverse subgroup of AML was AML M3, which showed the lowest levels of $H O X$ gene expression. This subgroup is characterized by the presence of the $P M L-R A R a$ fusion gene, which generates an aberrant retinoic acid receptor unresponsive to the physiological levels of this molecule. RUNX1RUNX1T1+, CBFb-MYH11+ and MLL-rearranged AML patients also showed unique $H O X$ gene expression patterns. $M L L$ rearrangements have been previously shown to have a determinant role on $H O X$ gene expression [44]. Moreover, we revealed that AML patients bearing the PML-RARa fusion gene had low expression levels of the HOX genes regardless of FLT3/ITD status. This finding is even more interesting considering that FLT3/ ITD has been shown to be associated with the upregulated expression of HOX genes in leukemia patients [33]. Therefore, we performed an analysis of a larger cohort of AML patients [34] from Erasmus MC-Sophia Children's Hospital and replicated the results drawn from our cohort of pediatric AML patients. This analysis showed that despite the overall upregulation of the $H O X$ genes in FLT3/ITD+ AML patients, HOX gene expression in FLT3/ITD + PML-RARa+ patients was significantly lower compared to the FLT3/ITD + patients without this fusion protein. Therefore, in this case, the PML-RARa fusion gene may be superior to FLT3/ITD with respect to its role in the process of malignant transformation. Based on these results, we suggest that AML-specific fusion oncoproteins may impact the upstream pathways that deregulate the $H O X$ genes, thereby acting as the major underlying factors of their characteristic expression patterns observed in leukemic cells.

Our analysis of the AML patients also showed significantly lower expression levels of HOXA in the SR compared with the HR patients (in accordance with a previous study [14]). These results suggest that the assessment of HOX gene expression patterns may allow for the prediction of aggressive cases of leukemia and may therefore be taken into consideration in risk stratification. However, we suggest that this observation is a 


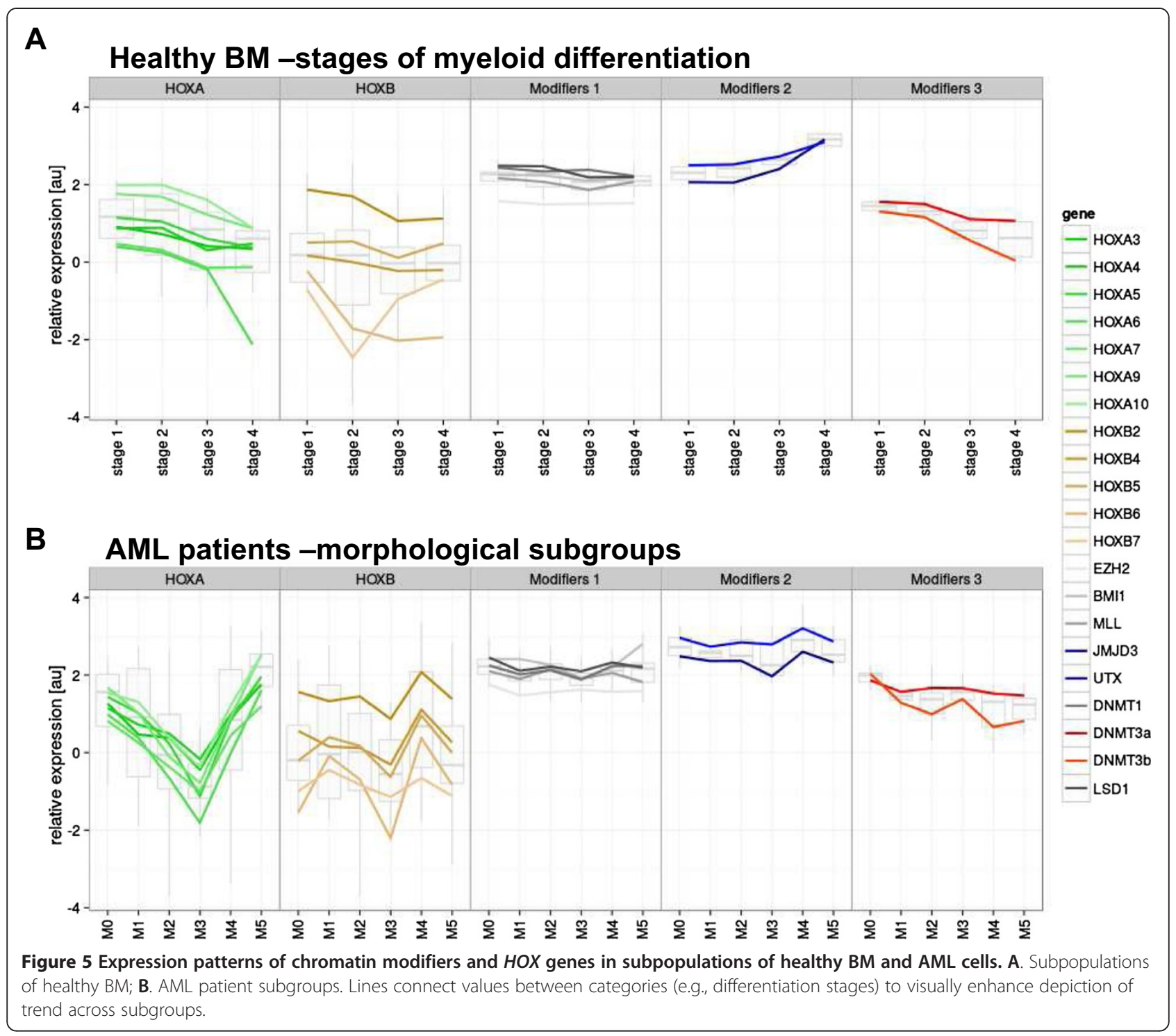

consequence of the allocation of patients with different molecular aberrations to particular AML risk groups (i.e., PML-RARa+ patients with the lowest HOXA gene expression levels being assigned to the SR group and $M L L+$ cases with the highest expression levels of $H O X A$ genes being allocated to the HR group) and not an independent prognostic factor.

Considering the profound contribution of chromatin modifiers to the embryonic regulation of $H O X$ genes and the essential roles of $H O X$ genes in hematopoiesis, the dysregulation of chromatin modifiers may deregulate the entire process of hematopoiesis and subsequently lead to malignant transformation. However, the exact roles of epigenetic modifications in the regulation of leukemic $H O X$ gene expression remain to be elucidated. It has recently been shown that $H O X$ genes possess unique chromatin regions called bivalent domains. These domains are characterized by the presence of both repressive (methylated H3K27) and activating (methylated H3K4) histone methylation marks and are found in genes poised to be activated according to cell-specific requirements [45]. To determine the role of chromatin modifiers in the regulation of $H O X$ genes in normal hematopoiesis and leukemogenesis, we analyzed the expression patterns of DNA methyltransferases, histone H3K27/ H3K4 demethylases, and selected PcG and TrxG genes in subpopulations of healthy BM cells and BM samples of patients with AML. We found an inverse correlation of histone demethylase (Modifiers 2) and DNMT (Modifiers 3) gene expression in normal and malignant hematopoiesis. In contrast to healthy hematopoiesis, we found an interesting correlation between chromatin modifier gene expression and that of the $H O X$ genes in the AML samples. The most pronounced correlation 


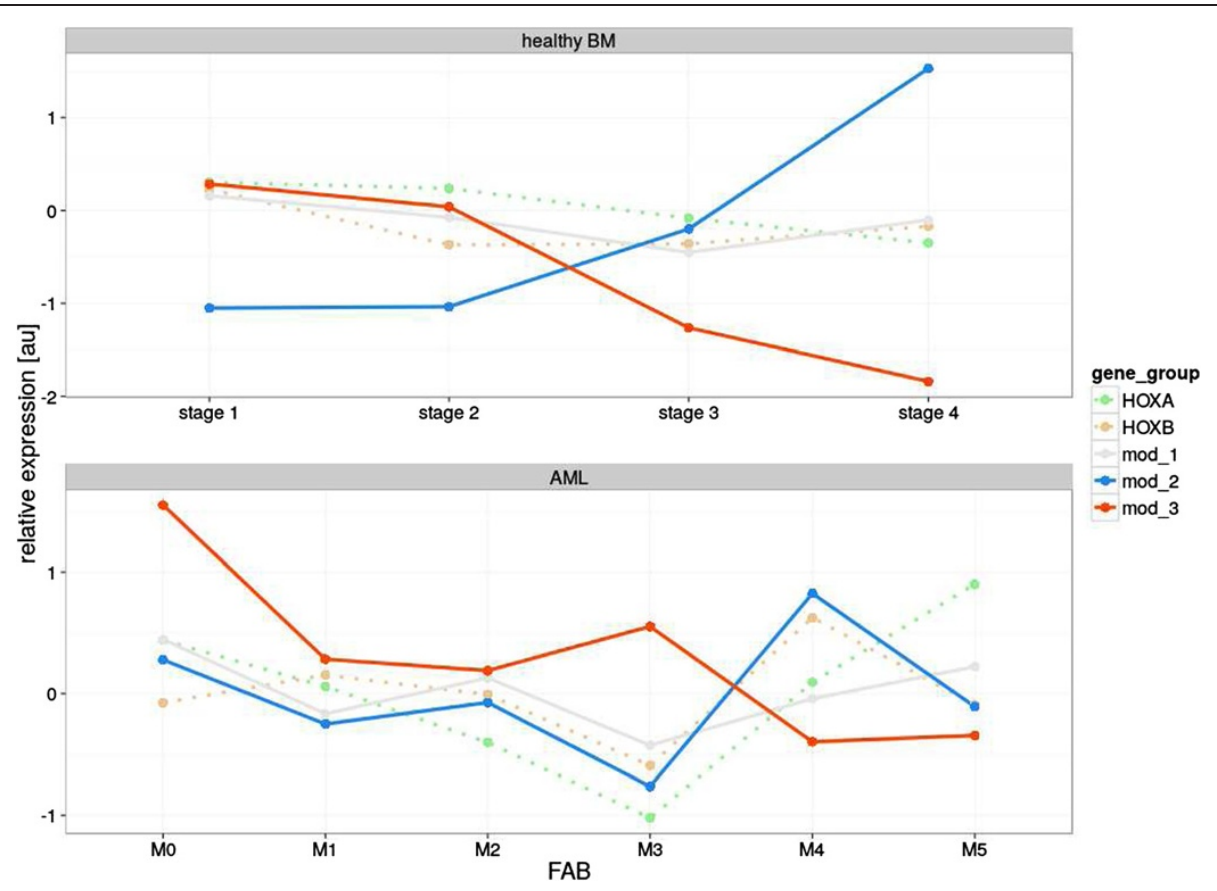

Figure 6 Relationship of expression patterns of chromatin modifiers and HOX genes in subpopulations of healthy BM and AML cells. Lines connect values between categories (e.g., differentiation stages) to visually enhance depiction of trend across subgroups.

was observed with the AML M3 subtype. The specific relationship of the $H O X$ genes with the epigenetic modifiers in this morphological subgroup could be affected by the presence of the PML-RARa fusion gene. In particular, $H O X$ gene expression was positively associated with the histone H3K27 demethylases, JMJD3 and UTX, and inversely correlated with DNMT3b. Notably, both $J M J D 3$ and UTX have recently been suggested to play roles in hematopoiesis [24,46]. Moreover, UTX has been shown to directly bind to the HOXB1 locus [21,24]. Taken together, the results implicate chromatin modifiers in the establishment of the aberrant leukemic expression of $H O X$ genes in pediatric AML patients.

Although the expression of $B M I 1$ was not altered during hematopoiesis, a Spearman correlation analysis showed that this gene was positively correlated with $H O X$ gene expression in the leukemic samples. It has been reported that BMII determines the proliferating abilities of the cells by inhibiting the 16 gene. HOXA9 was also shown to target $p 16$ and impair the senescence of cells [47]. Thus, the expression levels of the histone methyltransferase BMI1 are likely to reflect the proliferation statuses of leukemic cells without directly impacting $H O X$ gene expression [48].

Interestingly, the PML-RARa and RUNX1-RUNX1T1 fusion oncogenes have been shown to cooperate with repressive complexes, leading to alterations in chromatin architecture. PML-RARa causes profound changes in the epigenetic landscape, mainly by recruiting chromatin- modifying enzymes to target sequences or by the deregulation of their functions [49,50]. Furthermore, recent studies have shown that the degradation of the PMLRARa oncoprotein results in dramatic changes to the landscape of histone modifications [51]. Similarly, RUNX1RUNX1T1 has also been shown to recruit epigenetic modifiers to target sequences [52]. These findings together with our data suggest that AML-specific oncoproteins regulate $H O X$ gene expression through epigenetic modifications. However, further studies are needed to understand the roles of epigenetic modifiers in the regulation of normal as well as leukemic $H O X$ gene expression and their cooperation with AML fusion oncoproteins.

In summary, we found that the expression patterns of the $H O X$ genes in leukemic cells are not solely determined by their particular differentiation stages. Conversely, we assume that the specific molecular aberrations that are typical of AML are the major determinants of the leukemic expression patterns of the $H O X$ genes. Our results also demonstrate the differing contributions of epigenetic modifiers to $H O X$ gene expression in healthy and malignant hematopoiesis.

\section{Additional files}

Additional file 1: Table S1. Patients' characteristics.

Additional file 2: Figure S1. mRNA expression of particular HOXA and HOXB genes in subpopulations of healthy BM. 
Additional file 3: Figure S2. Correlation of HOXA, HOXB and chromatin modifier gene expression in subpopulations of healthy BM.

Additional file 4: Figure S3. mRNA expression of particular HOXA and HOXB genes in morphological subgroups of AML patients.

Additional file 5: Figure S4. mRNA expression of particular HOXA and HOXB genes in subgroups of AML patients defined according to molecular genetics.

Additional file 6: Figure S5. Unsupervised HCA of AML patients based on the epxression pattern of HOX genes.

Additional file 7: Figure S6. Comparison of individual HOX gene expression of SR and HR groups.

Additional file 8: Figure S7. Comparison of HOX gene expression pattern between AML M5 patients and sorted subpopulation of healthy BM (A. AML M5a vs. ID = M3; B. AML M5b vs. ID = M4).

Additional file 9: Figure S8. Correlation of HOX and chromatin modifier gene expression in AML patients.

\section{Competing interests}

The authors declare that they have no competing interests.

\section{Authors' contributions}

KSK performed majority of the sample processing and analyses and wrote the manuscript. KR was responsible for the GPCR analyses, and KF performed the statistical analyses. EM defined the crucial characteristics of the sorted subpopulations of the healthy BM cells and designed all of the FACS sorting experiments. MZ was responsible for the molecular characterization of the AML patients. HD and JT revised the manuscript and provided critical intellectual feedback. JaS was responsible for the clinical management of the patients. As a senior author, JuS coordinated all of the experiments, revised the manuscript and is the principal investigator of the whole study. CMZ, MvdHE and MF contributed by providing datasets and performing the gene expression profiling analyses of the replication sets. All authors read and approved the final manuscript.

\section{Acknowledgments}

The authors would like to thank the staff of the Czech Pediatric Hematology Working Group (CPH) centers for their cooperation. We are also grateful to our technicians (especially Pavel Semerak) for their kind help with the sample processing. This work was supported by Grant Agency of Czech Republic P304/12/2214. KR was supported by Grant Agency of Charles University GAUK 568213. JaS was supported by the Project of Ministry of Health, Czech Republic for the conceptual development of research organizations 00064203 (University Hospital Motol, Prague, Czech Republic). We acknowledge the contribution of samples from $A B$ and $D R$ and the support of the DCOG $(\mathrm{VdH})$ as shown in previous studies [34].

\section{Author details}

${ }^{1}$ CLIP-Childhood Leukaemia Investigation Prague, Department of Paediatric Hematology and Oncology, 2nd Faculty of Medicine, Charles University Praque, Prague, Czech Republic. ${ }^{2} \mathrm{CLIP}-C h i l d h o o d$ Leukaemia Investigation Prague, Department of Paediatric Hematology and Oncology, 2nd Faculty of Medicine, University Hospital Motol, Prague, Czech Republic. ${ }^{3}$ Department of Paediatric Hematology and Oncology, 2nd Faculty of Medicine, Charles University Prague and University Hospital Motol, Prague, Czech Republic. ${ }^{4}$ Department of Pediatric Oncology and Hematology, ErasmusMC-Sophia Childrens Hospital, Rotterdam, The Netherlands. ${ }^{5}$ Department of Hematology and Oncology, Medical University of South Carolina, Charleston, SC, USA.

${ }^{6}$ Department of Biochemistry, ErasmusMC, Rotterdam, The Netherlands.

Received: 18 September 2014 Accepted: 4 December 2014

Published online: 24 December 2014

\section{References}

1. Duboule $D$, Dolle $P$ : The structural and functional organization of the murine HOX gene family resembles that of Drosophila homeotic genes. EMBO J 1989, 8:1497-1505.

2. Scott MP, Tamkun JWHG 3rd: The structure and function of the homeodomain. Biochim Biophys Acta 1989, 989:25-48.
3. Mallo M, Wellik DM, Deschamps J: Hox genes and regional patterning of the vertebrate body plan. Dev Biol 2010, 344:7-15.

4. Vitiello D, Kodaman PH, Taylor HS: HOX genes in implantation. Semin Reprod Med 2007, 25:431-436.

5. Wellik DM: Hox patterning of the vertebrate axial skeleton. Dev Dyn 2007, 236:2454-2463.

6. Neville SE, Baigent SM, Bicknell AB, Lowry PJ, Gladwell RT: Hox gene expression in adult tissues with particular reference to the adrenal gland. Endocr Res 2002, 28:669-673.

7. Takahashi Y, Hamada J, Murakawa K, Takada M, Tada M, Nogami I, Hayashi $\mathrm{N}$, Nakamori S, Monden M, Miyamoto M, Katoh H, Moriuchi T: Expression profiles of $39 \mathrm{HOX}$ genes in normal human adult organs and anaplastic thyroid cancer cell lines by quantitative real-time RT-PCR system. Exp Cell Res 2004, 293:144-153.

8. Abramovich C, Humphries RK: Hox regulation of normal and leukemic hematopoietic stem cells. Curr Opin Hematol 2005, 12:210-216.

9. Sauvageau G, Lansdorp PM, Eaves CJ, Hogge DE, Dragowska WH, Reid DS, Largman C, Lawrence HJ, Humphries RK: Differential expression of homeobox genes in functionally distinct CD34+ subpopulations of human bone marrow cells. Proc Natl Acad Sci U S A 1994, 91:12223-12227.

10. Borrow J, Shearman AM, Stanton VP, Becher R, Collins T, Williams AJ, Dubé 1 , Katz F, Kwong YL, Morris C, Ohyashiki K, Toyama K, Rowley J, Housman DE: The $t(7 ; 11)(p 15 ; p 15)$ translocation in acute myeloid leukaemia fuses the genes for nucleoporin NUP98 and class I homeoprotein HOXA9. Nat Genet 1996, 12:159-167.

11. Diakos C, Xiao Y, Zheng S, Kager L, Dworzak M, Wiemels JL: Direct and Indirect Targets of the E2A-PBX1 Leukemia-Specific Fusion Protein. PLoS One 2014, 9:e87602.

12. Raza-Egilmez SZ, Jani-Sait SN, Grossi M, Higgins MJ, Shows TB, Aplan PD: NUP98-HOXD13 gene fusion in therapy-related acute myelogenous leukemia. Cancer Res 1998, 58:4269-4273.

13. Quentmeier H, Dirks WG, Macleod RAF, Reinhardt J, Zaborski M, Drexler HG: Expression of HOX genes in acute leukemia cell lines with and without MLL translocations. Leuk Lymphoma 2004, 45:567-574.

14. Drabkin H, Parsy C, Ferguson K, Guilhot F, Lacotte L, Roy L, Zeng C, Baron A, Hunger S, Varella-Garcia M, Gemmill R, Brizard F, Brizard A, Roche J: Quantitative HOX expression in chromosomally defined subsets of acute myelogenous leukemia. Leuk Off J Leuk Soc Am Leuk Res Fund, UK 2002, 16:186.

15. Starkova J, Zamostna B, Mejstrikova E, Krejci R, Drabkin HA, Trka J: HOX gene expression in phenotypic and genotypic subgroups and low HOXA gene expression as an adverse prognostic factor in pediatric ALL. Pediatr Blood Cancer 2010, 55:1072-1082.

16. Andreeff M, Ruvolo V, Gadgil S, Zeng C, Coombes K, Chen W, Kornblau S, Barón AE, Drabkin HA: HOX expression patterns identify a common signature for favorable AML. Leukemia 2008, 22:2041-2047.

17. Beuchle D, Struhl G, Müller J: Polycomb group proteins and heritable silencing of Drosophila Hox genes. Development 2001, 128:993-1004.

18. Raaphorst F, Otte A, Meijer C: Polycomb-group genes as regulators of mammalian lymphopoiesis. TRENDS Immunol 2001, 22:682-690.

19. Ono R, Nosaka T, Hayashi Y: Roles of a trithorax group gene, MLL, in hematopoiesis. Int J Hematol 2005, 81:288-293.

20. Jin L, Hanigan CL, Wu Y, Wang W, Park BH, Woster PM, Casero RA: Loss of LSD1 (lysine-specific demethylase 1) suppresses growth and alters gene expression of human colon cancer cells in a p53- and DNMT1(DNA methyltransferase 1)-independent manner. Biochem J 2013, 449:459-468.

21. Agger K, Cloos PAC, Christensen J, Pasini D, Rose S, Rappsilber J, Issaeva I, Canaani E, Salcini AE, Helin K: UTX and JMJD3 are histone H3K27 demethylases involved in HOX gene regulation and development. Nature 2007, 449:731-734.

22. Tsumagari K, Baribault C, Terragni J, Chandra S, Renshaw C, Sun Z, Song L, Crawford GE, Pradhan S, Lacey M, Ehrlich M: DNA methylation and differentiation: HOX genes in muscle cells. Epigenetics Chromatin 2013, 6:25.

23. Das ND, Jung KH, Choi MR, Yoon HS, Kim SH, Chai YG: Gene networking and inflammatory pathway analysis in a JMJD3 knockdown human monocytic cell line. Cell Biochem Funct 2012, 30:224-232.

24. Liu J, Mercher T, Scholl C, Brumme K, Gilliland DG, Zhu N: A functional role for the histone demethylase UTX in normal and malignant hematopoietic cells. Exp Hematol 2012, 40:487-498. e3.

25. Yang J, Fang X: Expression of DNMT1, DNMT3a, and DNMT3b in eutopic endometrium. Zhong Nan Da Xue Xue Bao Yi Xue Ban 2012, 37:94-99. 
26. Falini B, Mecucci C, Tiacci E, Alcalay M, Rosati R, Pasqualucci L, La Starza R, Diverio D, Colombo E, Santucci A, Bigerna B, Pacini R, Pucciarini A, Liso A, Vignetti M, Fazi P, Meani N, Pettirossi V, Saglio G, Mandelli F, Lo-Coco F, Pelicci P-G, Martelli MF: Cytoplasmic nucleophosmin in acute myelogenous leukemia with a normal karyotype. N Engl J Med 2005, 352:254-266.

27. Hollink IHIM, van den Heuvel-Eibrink MM, Arentsen-Peters STCJM, Zimmermann M, Peeters JK, Valk PJM, Balgobind BV, Sonneveld E, Kaspers GJL, de Bont ESJM, Trka J, Baruchel A, Creutzig U, Pieters R, Reinhardt D, Zwaan CM: Characterization of CEBPA mutations and promoter hypermethylation in pediatric acute myeloid leukemia. Haematologica 2011, 96:384-392.

28. Pollard JA, Alonzo TA, Gerbing RB, Ho PA, Zeng R, Ravindranath Y, Dahl G, Lacayo NJ, Becton D, Chang M, Weinstein HJ, Hirsch B, Raimondi SC, Heerema NA, Woods WG, Lange BJ, Hurwitz C, Arceci RJ, Radich JP, Bernstein ID, Heinrich MC, Meshinchi S: Prevalence and prognostic significance of KIT mutations in pediatric patients with core binding factor AML enrolled on serial pediatric cooperative trials for de novo AML. Blood 2010, 115:2372-2379.

29. Sano H, Shimada A, Taki T, Murata C, Park M-J, Sotomatsu M, Tabuchi K, Tawa A, Kobayashi R, Horibe K, Tsuchida M, Hanada R, Tsukimoto I, Hayashi $Y$ : RAS mutations are frequent in FAB type M4 and M5 of acute myeloid leukemia, and related to late relapse: a study of the Japanese Childhood AML Cooperative Study Group. Int J Hematol 2012, 95:509-515.

30. Van Lochem EG, van der Velden VHJ, Wind HK, te Marvelde JG, Westerdaal NAC, van Dongen JJM: Immunophenotypic differentiation patterns of normal hematopoiesis in human bone marrow: reference patterns for age-related changes and disease-induced shifts. Cytometry B Clin Cytom 2004, 60:1-13.

31. Kussick SJ, Fromm JR, Rossini A, Li Y, Chang A, Norwood TH, Wood BL: Four-color flow cytometry shows strong concordance with bone marrow morphology and cytogenetics in the evaluation for myelodysplasia. Am J Clin Pathol 2005, 124:170-181.

32. Kussick SJ, Wood BL: Using 4-color flow cytometry to identify abnormal myeloid populations. Arch Pathol Lab Med 2003, 127:1140-1147.

33. Roche J, Zeng C, Barón A, Gadgil S, Gemmill RM, Tigaud I, Thomas X, Drabkin $\mathrm{H}$ a: Hox expression in AML identifies a distinct subset of patients with intermediate cytogenetics. Leuk Off J Leuk Soc Am Leuk Res Fund, UK 2004, 18:1059-1063.

34. Hollink IHIM, van den Heuvel-Eibrink MM, Arentsen-Peters STCJM, Pratcorona M, Abbas S, Kuipers JE, van Galen JF, Beverloo HB, Sonneveld E, Kaspers G-JJL, Trka J, Baruchel A, Zimmermann M, Creutzig U, Reinhardt D, Pieters R, Valk PJM, Zwaan CM: NUP98/NSD1 characterizes a novel poor prognostic group in acute myeloid leukemia with a distinct HOX gene expression pattern. Blood 2011, 118:3645-3656.

35. Montavon T, Soshnikova N: Hox gene regulation and timing in embryogenesis. Semin Cell Dev Biol 2014, 34C:76-84.

36. Boyer $L$ a, Plath $K$, Zeitlinger J, Brambrink T, Medeiros $L$ a, Lee TI, Levine SS, Wernig M, Tajonar A, Ray MK, Bell GW, Otte AP, Vidal M, Gifford DK, Young $\mathrm{R}$ a, Jaenisch $\mathrm{R}$ : Polycomb complexes repress developmental regulators in murine embryonic stem cells. Nature 2006, 441:349-353.

37. Alharbi RA, Pettengell R, Pandha HS, Morgan R: The role of HOX genes in normal hematopoiesis and acute leukemia. Leukemia 2013, 27:1000-1008.

38. Cantile M, Schiavo G, Terracciano L, Cillo C: Homeobox genes in normal and abnormal vasculogenesis. Nutr Metab Cardiovasc Dis 2008, 18:651-658.

39. DU H, Taylor HS: Molecular regulation of mullerian development by Hox genes. Ann N Y Acad Sci 2004, 1034:152-165.

40. Beslu N, Krosl J, Laurin M, Mayotte N, Humphries KR, Sauvageau G. Molecular interactions involved in HOXB4-induced activation of HSC self-renewal. Blood 2004, 104:2307-2314.

41. Lawrence HJ, Helgason CD, Sauvageau G, Fong S, Izon DJ, Humphries RK, Largman C: Mice bearing a targeted interruption of the homeobox gene HOXA9 have defects in myeloid, erythroid, and lymphoid hematopoiesis. Blood 1997, 89:1922-1930.

42. Izon DJ, Rozenfeld S, Fong ST, Kömüves L, Largman C, Lawrence HJ: Loss of function of the homeobox gene Hoxa-9 perturbs early T-cell development and induces apoptosis in primitive thymocytes. Blood 1998, 92:383-393.

43. Kappen C: Disruption of the homeobox gene Hoxb-6 in mice results in increased numbers of early erythrocyte progenitors. Am J Hematol 2000 65:111-118.
44. Hess JL: MLL: a histone methyltransferase disrupted in leukemia. Trends Mol Med 2004, 10:500-507.

45. Bernstein BE, Mikkelsen TS, Xie X, Kamal M, Huebert DJ, Cuff J, Fry B, Meissner A, Wernig M, Plath K, Jaenisch R, Wagschal A, Feil R, Schreiber SL, Lander ES: A bivalent chromatin structure marks key developmental genes in embryonic stem cells. Cell 2006, 125:315-326.

46. Ntziachristos P, Tsirigos A, Welstead GG, Trimarchi T, Bakogianni $S, X u L$, Loizou E, Holmfeldt L, Strikoudis A, King B, Mullanders J, Becksfort J, Nedjic J, Paietta E, Tallman MS, Rowe JM, Tonon G, Satoh T, Kruidenier L, Prinjha R, Akira S, Van Vlierberghe P, Ferrando A a, Jaenisch R, Mullighan CG, Aifantis I: Contrasting roles of histone 3 lysine 27 demethylases in acute lymphoblastic leukaemia. Nature 2014, 514:513-517.

47. Martin N, Popov N, Aguilo F, O'Loghlen A, Raguz S, Snijders AP, Dharmalingam G, Li S, Thymiakou E, Carroll T, Zeisig BB, So CWE, Peters G, Episkopou V, Walsh MJ, Gil J: Interplay between Homeobox proteins and

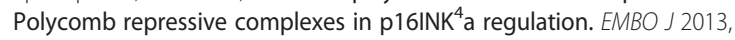
32:982-995.

48. Lessard J, Sauvageau G: Bmi-1 determines the proliferative capacity of normal and leukaemic stem cells. Nature 2003, 423:255-260

49. Di Croce L, Raker VA, Corsaro M, Fazi F, Fanelli M, Faretta M, Fuks F, Lo Coco F, Kouzarides T, Nervi C, Minucci S, Pelicci PG: Methyltransferase recruitment and DNA hypermethylation of target promoters by an oncogenic transcription factor. Science 2002, 295:1079-1082.

50. Grignani F, De Matteis S, Nervi C, Tomassoni L, Gelmetti V, Cioce M, Fanelli M, Ruthardt M, Ferrara FF, Zamir I, Seiser C, Lazar MA, Minucci S, Pelicci PG: Fusion proteins of the retinoic acid receptor-alpha recruit histone deacetylase in promyelocytic leukaemia. Nature 1998, 391:815-818.

51. Martens JHA, Brinkman AB, Simmer F, Francoijs K-J, Nebbioso A, Ferrara F, Altucci L, Stunnenberg HG: PML-RARalpha/RXR Alters the Epigenetic Landscape in Acute Promyelocytic Leukemia. Cancer Cell 2010, 17:173-185.

52. Fu L, Huang $W$, Jing $Y$, Jiang $M$, Zhao $Y$, Shi J, Huang $S$, Xue $X$, Zhang $Q$, Tang J, Dou L, Wang L, Nervi C, Li Y, Yu L: AML1-ETO triggers epigenetic activation of early growth response gene $I$, inducing apoptosis in $t(8 ; 21)$ acute myeloid leukemia. FEBS J 2014, 281:1123-1131

\section{Submit your next manuscript to BioMed Central and take full advantage of:}

- Convenient online submission

- Thorough peer review

- No space constraints or color figure charges

- Immediate publication on acceptance

- Inclusion in PubMed, CAS, Scopus and Google Scholar

- Research which is freely available for redistribution

Submit your manuscript at www.biomedcentral.com/submit 